\title{
Strengthening financial innovation in energy supply projects for rural exploitations in developing countries
}

\author{
Carlos Rodríguez Monroy, Antonio San Segundo Hernández \\ Department of Business Administration, School of Industrial Engineering, Universidad Politécnica de Madrid. \\ José Gutierrez Abascal, 2, 28006 Madrid, Spain \\ Department of Business Administration, School of Industrial Engineering, Universidad Politécnica de Madrid, \\ Avda. San Luis, 77, 28033 Madrid, Spain
}

\begin{abstract}
Sustainable energy supply models are needed to achieve the Millennium Development Goals established by the United Nations for 2015. On the other hand, sustainability of agricultural exploitations in rural areas is a pre-requisite to achieve the objective of halving the proportion of people that lives in poverty, and productivity of such exploitations is closely related to energy supply. This article analyses the results of a survey of experts, suggesting that there may be good chances to innovate in the financing of agricultural electrification projects in developing countries. The experts' opinion suggests that new sources of financing could be mobilised and oriented towards the promotion of sustainable initiatives in developing countries. Financial mechanisms should be adapted to the characteristics of decentralised systems of energy production with renewable sources or with mixed technologies, in order to overcome the barriers derived from the high initial price of the applications, and to the specific conditions of the agricultural sector. The participation of funds from the beneficiaries and the incorporation of the beneficiaries in the initial phases of project organisation would allow for the development of productive solutions with a higher potential to generate resources and to articulate sustainable proposals.
\end{abstract}




\section{Contents}

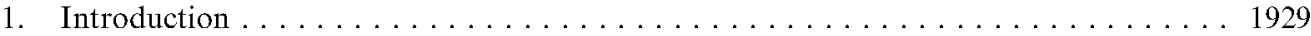

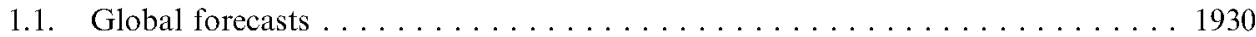

1.2. Conventional approaches and lessons learned . . . . . . . . . . . . . 1930

2. Critical factors for sustainability of rural energy projects $\ldots \ldots \ldots \ldots \ldots \ldots$. . . . 1930

3. The survey . . . . . . . . . . . . . . . . . . . . . . . . . . . 1931

4. Analysis and comments on the survey results . . . . . . . . . . . . . . . . 1934

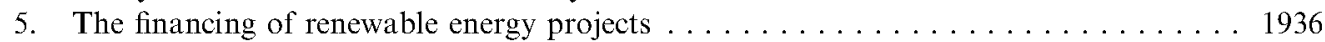

6. Barriers for success in rural energy electrification projects . . . . . . . . . . . 1939

7. Initiatives and proposals . . . . . . . . . . . . . . . . . . . . . . 1939

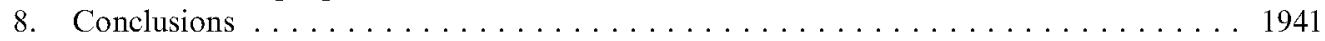

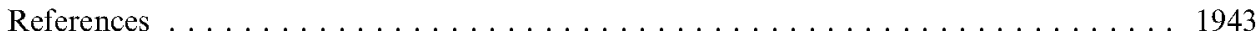

\section{Introduction}

The objective of this article is to make a contribution to the understanding of the technological, social, political, and economic aspects that influence electrification projects in rural areas, and to develop proposals and alternatives to improve the efficiency of international cooperation in the energy field. There is a need to review the present models of electrification taking into consideration the technological improvements, the advances carried out in industrialised countries to organise the energy markets, and the new tools offered by financial engineering.

In this article, we present some of the main conclusions obtained from a survey, carried out among experts throughout the entire world, about the main elements that influence the sustainability of electrification projects in rural areas of developing countries; special attention is given to the financial aspects. These conclusions may be of interest for improving the sustainability of agricultural energy projects in developing countries.

According to the International Energy Agency (IEA), almost 2000 million people currently have no access to basic electric services this figure shows that we are far from universal electrification. The main energy problem in rural areas, as well as in many urban areas in Africa, Asia and Latin America, is related to the accessibility and availability of modern energy services. Indeed, energy services play a basic role in the improvement of quality of life and are specially important in the case of rural agricultural exploitations.

In order to reach the goal of reducing by onehalf the proportion of people that live in extreme poverty, there is a need to increase the productivity of rural farms. A prerequisite for increasing farm productivity is the access to electricity in appropriate conditions, especially in the developing countries.

Because of these reasons, finding ways to improve the accessibility of electricity supply to the poorest segments of the population, especially in rural areas, has become a priority. Although the problem of energy supply does not only affect remote regions, but also pockets of poverty in peri-urban and urban areas, the need to review the models of electrification seems to be greater in the case of rural areas. 


\subsection{Global forecasts}

IEA estimates that in the next 30 years, the global investments in energy infrastructure will reach 16 trillion dollars. There is a good opportunity to reorient an increasing proportion of these investments towards renewable energies. In the same period, the demand for energy will be increased by 60 percent and, if the present energy supply growth trend is not modified, we will not be able to provide enough energy to large areas of the world.

On the other hand, the same energy forecasts suggest that it may be possible to balance the different objectives of sustainable development. The appropriate uses of energy requires the efficient use of natural resources, a higher confidence in renewable applications and the rapid development of new technologies, which are more efficient and less polluting. The analyses indicate also that the potential contribution of renewable energies in decentralised applications is being undervalued, and that a greater participation in this kind of project is currently economically viable

\subsection{Conventional approaches and lessons learned}

Conventional electrification by means of centralised energy plants and distribution lines often ignores remote rural populations, because their demand is geographically sparse and quantitavely small compared to urban and peri-urban populations.

The proposed solutions for rural populations frequently consider flat rates and subsidies to fossil fuels and conventional uses These policies may generate important transfers of income among different consumers of the energy supply, distorting the perception of the real costs incurred which affect the profitability of agricultural projects.

Among the lessons learned from the international projects which started in the 1980s, the following may be emphasised

- It is necessary to improve the coordination and exchange of information among the international community participating in the cooperation projects, in order to avoid duplication of efforts or the squandering of resources.

- It is possible to improve the coherence of the projects, regarding the policies of fighting against poverty and achieving agricultural development.

- The participation of the national governments of developing countries is fundamental to guarantee the long-term sustainability of the cooperation projects and, in this sense, it is necessary to increase the coordination between the international donors and the local administrations.

- The available information about the pilot projects scheduled in the last 20 years is dispersed and therefore misused. It is necessary in this sense to combine efforts to evaluate the main lessons learned from these projects.

- The main factors relevant to the sustainability of the interventions are the long-term financial equilibrium of running exploitations, the orientation of the proposals according to the demands of the beneficiaries and the existence of stable regulatory frameworks.

\section{Critical factors for sustainability of rural energy projects}

The consumption of energy in rural areas is generally very small; therefore, small-scale energy generation alternatives are important to meet these needs. The use of small 
decentralised generation systems based on renewable sources of energy, as well as hybrid systems that also make use of fossil fuels, is a suitable solution and often the only appropriate solution in areas in which the conventional approaches to electrification are not economically viable. Renewable energies have, therefore, a high potential to effectively address at the same time the challenges of energy scarcity, security of supply and rural development.

In urban areas, it is often the high prices of getting connected to the grid and the price of supply that make the access to electricity supply prohibitive. In the urban segment, the priority would be to achieve the economic sustainability of electric service by fixing realistic prices and adequately distributing cross-subsidies. In the case of rural supply the problem is different, given that conventional solutions are not always financially viable. This is often due to the peculiarities of consumption in these areas.

The provision of energy services in remote rural areas in which agricultural services need to be reinforced requires therefore innovative approximations from the point of view of the solutions offered and, especially, it requires considering the demand for final uses.

It is also needed to better integrate the local communities and other agents in the programs of rural electrification. From the point of view of demand, the programs of rural electrification will only be sustainable if the integration of the local communities in the process of selection of the best alternatives is maximised. From the supply point of view, the integration of new agents in the task of extending the energy supply can promote an improvement in the coordination of efforts.

As Boyle points out, the limited environmental impact and scalability of renewable energies provide an adequate solution for electrification in rural areas. The decreasing trend of production costs of renewable technologies, together with an increase in the efficiency of the applications make them economically viable for the generation of electricity in rural environments.

The use of renewable technologies for solutions of distributed generation is an adequate answer to meet the needs of energy services in remote areas in which agricultural industry is the main source of income. It is also an alternative to network electrification, although financial models which better adapt the specific features of these technologies to the social and economic circumstances of the beneficiaries are needed, specially in those applications that are extensive in capital.

While considering new tools and models of financing, it is necessary to question the role of the main agents involved in the agenda of development, putting special emphasis on the relations of the private sector with the rest of the institutions involved: governments, nongovernmental organisations for development and multilateral international agencies.

The problem of energy supply with renewable technologies in developing countries is often impeded by two controlling or determining factors: the need to accelerate the process of technology transfer in an efficient way and the requirements of financing the selected applications

\section{The survey}

The Department of Business Administration at the School of Industrial Engineering of the Universidad Politécnica de Madrid undertook a research project on the field of electrification solutions. The research focused on the analysis and revision of the main aspects that influence the sustainability of energy supply, and on the main factors which 
have a positive influence on the long-term viability of the projects. Conclusions from this research project can be of direct application to electrification projects of agricultural exploitations in rural areas. A summary of the methodology and results is presented in the following paragraphs.

An analysis campaign was carried out at the end of 2004. The exercise consisted of distributing and monitoring an e-mail questionnaire to a large group of experts in the fields of energy supply in developing countries, rural energy supply, regulatory issues and financial aspects of electricity demand The survey covered the main geographical regions of the world (see Fig. 1), as well as the diverse protagonists of energy cooperation projects (multilateral institutions, private companies, universities, non-governmental organisations of development and researchers). The survey answers were given in a scale of ' $1-5$ ', with ' 5 ' being the maximum or more important value.

For the distribution phase of the questionnaire, the initiative Global Village Energy Partnership (www.gvep.org) was contacted. This initiative is supported by the World Bank in conjunction with Energy Sector Management Assistance Programme (ESMAP), the US Agency for International Development, the US Department of Energy, the National Renewable Energy Laboratory and the Winrock International Programme. This community of experts and analysts agreed to help to disseminate the questionnaire, inviting its members to participate in the research. The questionnaire was made available in the home page of the initiative during several weeks. It can be concluded that the questionnaire had a favourable acceptance, given that a total of 185 answers were received, which represents an estimated participation of 21.6 percent. Answers from 69 countries were received corresponding to more than 140 different organisations.

The results of the survey show that, for this community of experts and analysts, the main factors to improve the long-term viability of the projects of electrification are, in order of relevance: the financial sustainability of the solutions (most important, according to the 85 percent of those interviewed), the focus on demand-side needs for energy services and the existence of stable regulatory frameworks (Fig. 2).

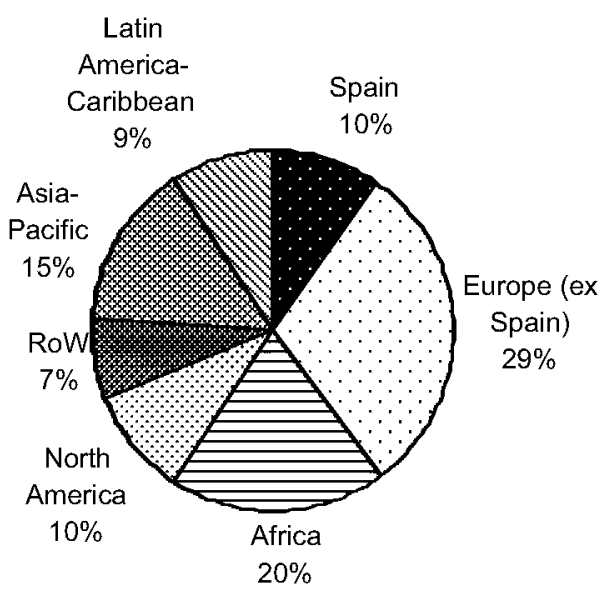

Fig. 1. Responses by geographical region. 


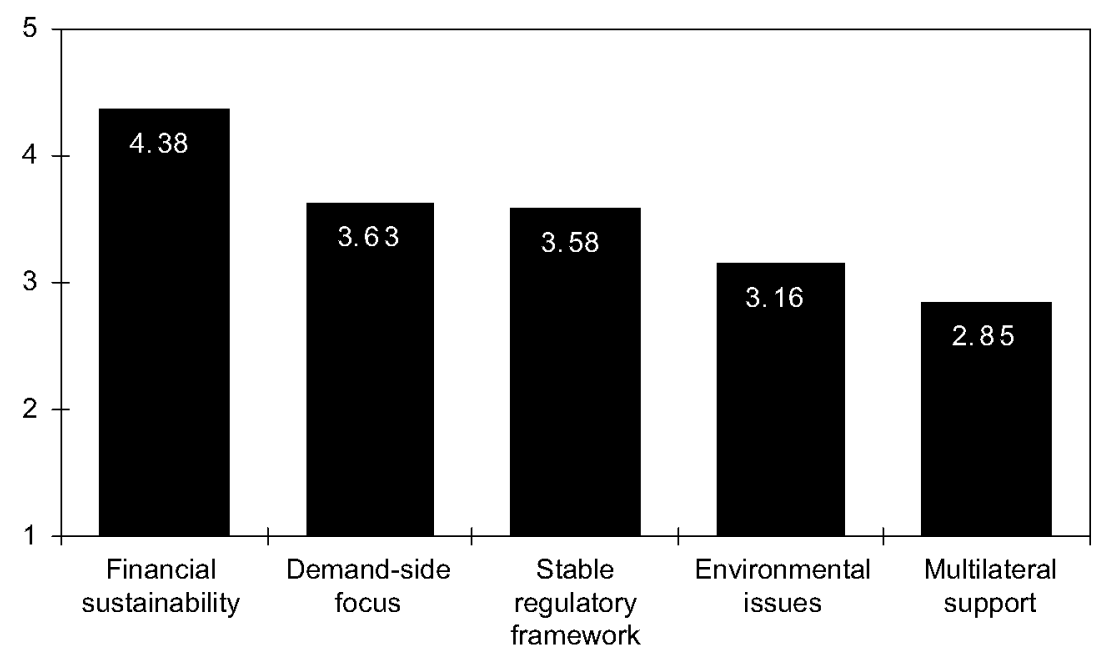

Fig. 2. Main parameters that influence sustainability of electrification projects (average values).

Particularly, when talking about renewable energies, the innovation in the financial area and local involvement of private sector seemed to be the main aspects that have greater potential to increase the penetration of these technologies in developing countries. Concerning the most appropriate mechanisms to assure the long-term sustainability of the projects of electrification with renewable energies, the agreements among public-private agents were considered the most adequate instruments.

With regard to the agents that participate in electrification projects, the lack of profitability and the inadequate regulatory frameworks would be, according to the research conducted, the main concerns of the private sector when considering the possibility of participating in the projects of rural electrification

When asked about factors relevant to the long-term financial viability of the projects of electrification with renewable energies, the majority of the experts considered that the existence of adequate micro-finance plans, as well as the possibility to develop productive applications linked with the systems of energy supply were the proposals that had the greatest potential (Fig. 3). These conclusions should be taken into account when planning agricultural projects in rural areas.

From the perspective of promoting renewable energies projects in developing countries, the majority of participants considered that the Renewable Energy Funds were the most adequate financial instrument. The employment of project financing solutions was the second alternative considered. From the point of view of the demand for energy services, and considering the method of financing in final applications, the revolving funds were considered the most appropriate instrument. Commercial financing, as well as the instruments of lease or postponement of purchase, did not seem as attractive in the case of supplying energy from renewable sources. Finally, the majority of experts estimated that financial innovation, institutional support in the area of financing and local strengthening were the main initiatives that would have very high potential to increase the mobilisation of additional resources to finance energy supply employing renewable technologies (Fig. 4). 


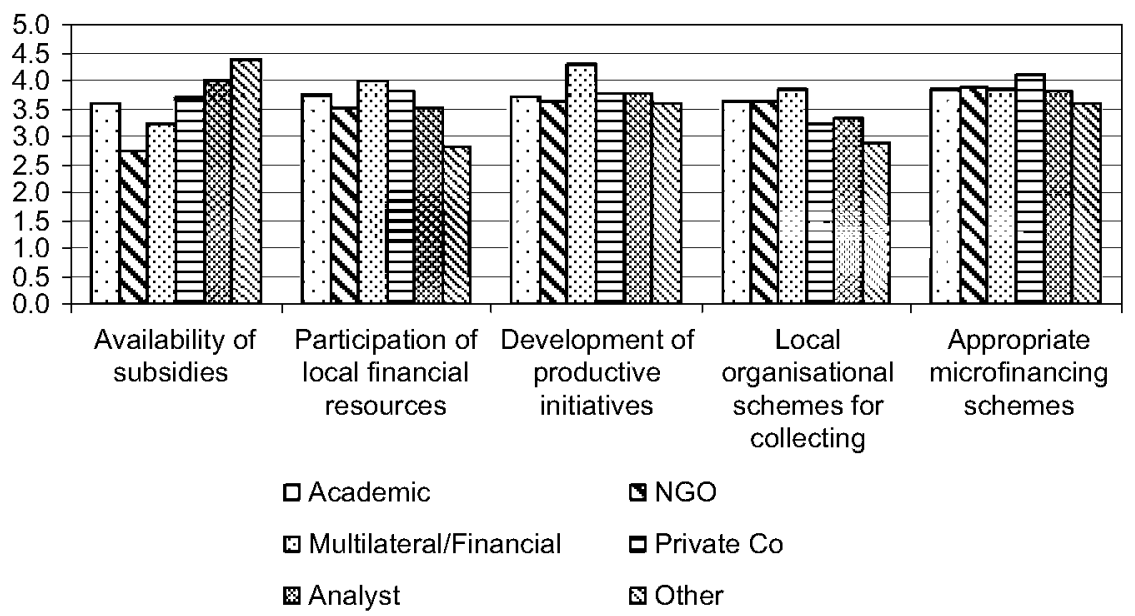

Fig. 3. Proposals for long-term financial viability of electrification projects using renewable energies (average values by group of respondents).

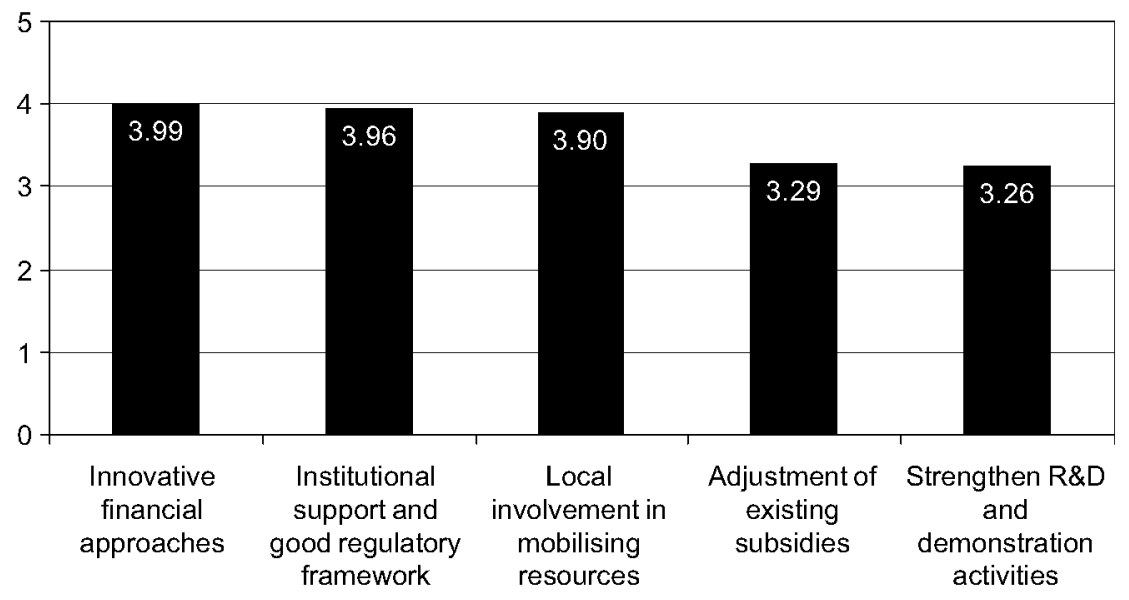

Fig. 4. Proposals to increase resource mobilisation to finance renewable electrification projects in developing countries (average values).

\section{Analysis and comments on the survey results}

The financial sustainability should consider as basic principle the need to transfer the total costs of the applications to the final users, that is to say, that the developed mechanisms of financing should try to recover the costs of the projects in the long-term and during the whole life-cycle of the projects. This is of enormous importance when dealing with agricultural exploitations in which adapting the financing requisites to the availability of incomes because of seasonal production need to be taken into account.

The experiences that have taken place in this sense, Martinot et al. indicate that, in the final analysis, payment capacity is not a problem: the barriers found are related, 
instead, to the initial costs of energy provision systems, and to the possibility of finding the financial and organisational mechanisms that enable the development of productive solutions based on renewable energy supply.

Five important challenges for the penetration of sustainable solutions in rural environments ("the 5 P's") may be identified: prices, political decision, potential of financing, energy products and prospects for the investment. An adequate combination of research and development, reforms in the public sector, and the rationalisation of tariffs and subsidies, as well as the establishment of legal predictable regulatory frameworks would be able to increase the availability of resources to finance applications of distributed energy supply.

For the development of sustainable energy projects in the long-term, specially for agricultural purposes, it is necessary to emphasise the cost-benefit analysis in the whole cycle of the project. On the other hand, generally speaking, market decisions are based on short-term planning. Therefore, project design must reserve an appropriate role, both for the markets and for institutional involvement.

When considering new sources of financing for the agricultural sector, it is important to improve the basic conditions needed to attract investments towards developing countries. This is certainly a difficult challenge presenting numerous difficulties, but it is necessary to undertake such a challenge in an urgent way.

Taking into account the previous results, the main proposal would be to enhance the creation and development of new mechanisms and instruments oriented towards the availability of dedicated funds to reach the energy needs of agricultural industry. Very often it is not a matter of lack of funds, but of having the capacity to reorient the resources towards the desired objectives. Solutions should be oriented towards the adaptation and application of already established financial instruments (bonds, investment funds, etc.) towards new and emerging areas of investment, as well as towards the efficient use of these mechanisms.

Concerning credit financing for end users and the interrelation among the debt and aid programs, it is possible to launch significant actions to optimise resource management in order to bring funds to the true protagonists of energy supply projects. The multilateral institutions of development can play an important role in granting loans to the projects through the usual commercial networks, contributing additionally to reducing the risks of exposition to the interventions.

Agricultural electrification projects should be approached as processes of energy innovation, in which the renewable technologies have the potential to meet the energy needs of rural areas not connected to the main power network. Efforts are being developed to strengthen the ways of financing, though it would be possible to implement additional actions regarding the coordination, financial innovation and strengthening of initiatives, starting with the activities of research and development and of technological transfer (Fig. 5).

Impulsing innovative models of financing and contracting, where the costs and risks can be shared by the different participating agents and where the peculiarities of the cash cycle of the beneficiaries are properly taken into account, should be considered a priority in the field of international cooperation. This would require changing the focus of financing from a supply perspective to a focus on meeting the needs of funding of the demand-side. The strategies to maximise the generation of available resources should keep in mind the need to optimise the management of public funds, and the opportunities derived from the participation of the private sector in public-private intervention agreements. 


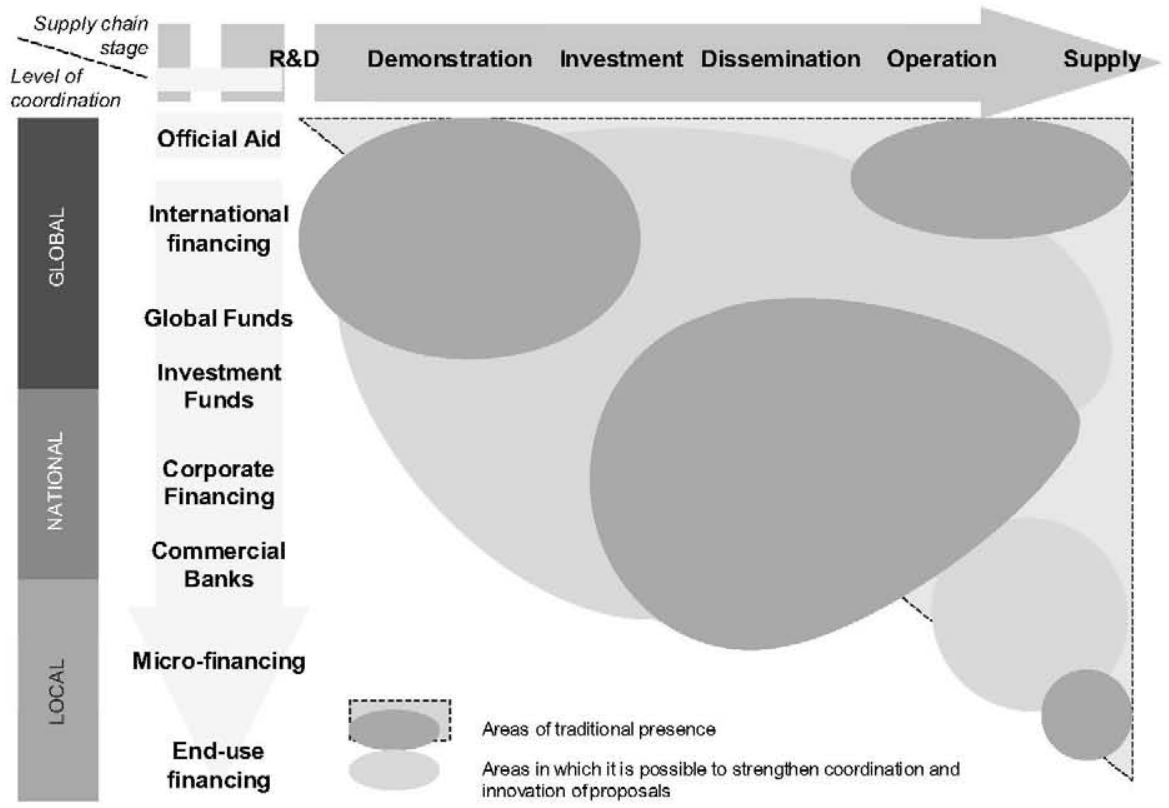

Fig. 5. Areas to be reinforced in the financing of agricultural electricity supply.

In the same way, once the governments assume the task to develop policies that improve market conditions, the private sector would be responsible for investing in projects of rural electrification, specially for agricultural purposes. Therefore, there is a challenge of innovation during the next decades, especially in the areas of financial models and resource management in rural exploitations. Adequate project blueprints would only be achieved by combining an adequate political promotion of new proposals, as well as strategies to reconsider the existing mechanisms of financing (subsidies, role of financial institutions, aid funds, etc.).

One of the conclusions that may be extracted is that an adequate restructuring of the funds devoted to support the developing countries would allow a better use of resources in the field of energy supply in rural applications. The redistribution of existing subsidies, the reconsideration of public funds used to support conventional energies, or the integration of the sustainable energy supply actions with the strategies of the fight against poverty in developing countries could also be part of the project design tool box. Regarding conventional commercial financing and the market of guarantees, the involvement of international institutions acting as intermediaries may contribute to a better perception of the real risks of the projects, helping to reduce the overall cost of projects. Plans of insured financing, in which different groups of assets are negotiated in an integrated form in different regions and with different levels of risk should be considered. A greater coordination among the financial institutions, the international guarantee agencies as well as the credit agencies would help in this sense.

\section{The financing of renewable energy projects}

International aid funds should contribute to develop a framework of conditions that could promote private investment in the energy and agricultural sectors of developing 
countries. For this purpose, it may be necessary to create solutions that explore the limits of innovation in the financial aspects of energy supply. In any case, coordination should be increased first among the participating agents: international institutions, private sector, non-governmental organisations for development and, especially, the governments of developing countries.

It is necessary to bear in mind that supporting the dissemination of renewable energies in developing countries does not mean using the same models as in industrialised countries. The exploration of alternatives for the provision of energy services that make use of the local resources and technologies and that taken into account organising solutions developed by the beneficiaries is often needed

In the area of financing, the design of adapted solutions for low-income communities and small businesses should consider models of best practices that are being employed in other development project areas.

When selecting the most adequate mechanisms of financing, the economic situation of the beneficiaries needs to be taken into account, so that the barriers of high initial costs that prevent a wider use of renewable technologies can be addressed. In general, micro-financing solutions should be incorporated in the models of cooperation in energy supply. Besides the conventional process of rural electrification, based on the extension of the existing network, it is necessary to consider models for small-scale distributed generation that are often more suitable for agricultural energy projects, especially in rural areas.

The objectives of sustainable development in energy terms are related to the satisfaction of human needs at a domestic level, to the provision of sufficient energy services to develop small-scale productive activities, and to the existence of financial models that make it possible to face the cost of energy consumption according to the cash cycle of the beneficiaries. In each case, it is necessary to identify the financing and organisation options that are more adequate depending on the technological characteristics of the interventions

The search for sustainability points out the need to progress from the traditional systems based on the long-term backing of the governments to the search of plans leading to the development of a market for renewable energies in developing countries. These plans should have as a pre-requisite the participation of the beneficiaries in the financing of the energy systems selected. For this task it is necessary to attract new agents, especially from the private sector and financial intermediaries, so that they can promote a variety of energy alternatives by providing access to those who cannot afford the barrier of the initial cost of energy supply.

Rural electrification, specially for agricultural purposes, is not the kind of investment that directly appeals to private investors seeking to maximise their performance, though there are cases in which the participation of private agents with the support of local institutions has been successful It is necessary to understand that private financing can act as an element that complements a mix of funds, guarantees, aids and debt offered by international, regional or local institutions.

There may be no single, unique financial instrument or universal proposal for the organisation of the energy supply, which would make it possible to obtain the best solutions for each energy problem. An adequate combination of better practices and instruments for organisation, regulatory changes and, especially, for the financing of the projects may be required. 
The experiences carried out to finance remote rural energy production systems for agricultural purposes with micro-credit, payment by service or rent for use, are still recent, but the results of these practices allow us to extract diverse conclusions The most significant conclusion is that the real capacity of end users to afford the total cost of energy is higher than thought to be at first. Priority efforts should thus be directed to diminishing the barrier of high costs of installation of energy applications, especially for renewable technologies.

In the case of network applications, the financing fundamentally depends on the capacity to obtain a flow of predictable and stable payments; the most common plans are those that allow an appropriate assignment of risks among the participating agents. On the other hand, in the case of isolated applications, the problem is satisfying the requisites of many small projects, in which the assignment or pooling of risks has not been carried out clearly. In this sense, while the financing of network projects could be classified as local, in the case of out-of-network systems we would have to deal with a wide spectrum of financing along the whole supply chain.

Long-term, sustainable financing solutions should involve private sector and local organisations, with adequate conditions to encourage the mobilisation of investments. The reinforcement of relationships between the private and public sectors, as well as the use of the special capacities that could be offered by the energy based non-governmental organisations for development, should be part of the foundation of the rural electrification programs undertaken in developing countries.

In the area of renewable systems, the models and instruments of financing are highly dependent on the needs and scale of the projects. Thus in projects of large or medium size, generally connected to the network, the basic applications are systems in the range of 1-20 MW operated by commercial companies or by independent power producers. In these cases the basic problems of financing are related to the risk perceived by the channels of conventional credit. These channels are not used to working with projects in areas without a record of credit, led by intermediaries with less experience that the conventional suppliers of energy.

Concerning medium or small size systems (less than $1 \mathrm{MW}$ ), which are especially suitable for agricultural exploitation purposes where mini-networks that connect individual renewable systems are operated, the main financial aspect is the credibility of users. Large international corporations do not have an interest in promoting these channels of relation with the end users, because of their low profit value, and - besides - the small promoters of applications lack the economic strength to support the investments needed to carry out these supply networks.

In this case, the financial models to be strengthened could be of two different types. In those cases in which improving the sustainability of agricultural projects is a priority for the national authorities, the approach would be to offer concessions in adequate conditions to the private sector or local cooperatives. In other cases, the model of financing would be focused in aggregating the demand and in partially transferring the problems of financing to the capacity of organisation of the local communities, which would assume part of the risk of project financing.

Finally, in small-scale projects based in general on individual systems, the challenge of financing consists in the aggregation of small loans and in the relationship with individual communities that may not have a record of risk, a culture of payment, or, in many occasions, a capacity of collateralisation of the loans. In these cases, generic models of 
financing make use of the techniques of micro-credit to acquire the equipment, Harper (2003). The role that the intermediaries (energy supply companies, suppliers of equipment, micro-credit organisations, etc.) play, and the commitment of the beneficiaries (associations, community organisations, cooperatives of credit or companies of local collection) are the basic elements that influence the long-term sustainability of the projects.

\section{Barriers for success in rural energy electrification projects}

Among the basic tools needed to reach the objectives of universal electrification and of sustainable energy progress in the agricultural field is the development of adequate normative and regulatory frameworks. These frameworks need to reckon with the technological improvement of renewable energies and with the participation of the private sector. The regulatory frameworks of the developing countries were created during the last 20 years of the past century, and in them, priority was placed on conventional energies; in this sense, it is of special significance the existence of important subsidies, tax exemptions or incentives for energy development with fossil technologies.

Sustainable energy supply requires a significant change towards the increase of diversity, moving from the conventional systems (characterised by having few agents and large infrastructure projects) towards a multi-agent focus, characterised by a higher dispersion of the installations and a greater number of participants. The change faces hurdles in the regulatory, financial, legal, and institutional fields. These barriers currently prevent improving the efficiency of the process of cooperation and energy planning, specially in the area of rural development. Furthermore, this transition process requires an important change in the focus of the interventions, away from the energy supply and towards the final demand for energy services that would match the characteristics of the agricultural exploitations. Good practices of government and a solid management of the energy markets are requirements to attract new capital to the energy sector

The main barriers to renewable energies projects for agricultural solutions could be summarised as follows: lack of infrastructures, inadequate planning of projects, financial restrictions, high initial cost of solutions, lack of adequate incentives, political and institutional barriers, lack of coordination among projects, diversity of interests and inertia, lack of exchange of experiences and need of consciousness-raising

The existence of solid and stable regulatory frameworks should be considered a starting point for any proposal of universal energy service, especially in developing countries.

Solutions for rural electrification for agricultural purposes have traditionally been small local interventions, carried out by development organisations or cooperatives, These interventions have had limited success, to a large extent because of lack of participation of the beneficiaries in the decision making process Excluding local agents from the models of project organisation and financing may create a barrier to the long-term sustainability of the projects.

\section{Initiatives and proposals}

In geographic areas with very limited access to energy supply or with low purchasing power capacity, the solutions should be initially focused towards applications of a public character, which allow the use of community resources. This initial focus would later allow for enlarging the access of the individual beneficiaries to the energy supply, while also 
increasing the knowledge of the limitations and the features of the implemented solutions. In order to reinforce the sustainability of energy production, it is also needed to adapt the solutions to the peculiarities of the agricultural industries in each area.

For renewable energy projects, developing countries need to mobilise domestic and external resources. A larger attraction of capital would be more likely if adequate incentives to encourage the participation of private enterprises are provided, and a climate of risk reduction and of support to the interventions is generated. Cooperation among the multilateral financial institutions, the agencies of bilateral aid and the agencies of export credit can play a key role in improving the economic conditions for these projects. The process of sustainable electrification of rural areas sets a challenge in which the strategies of both private and public sectors should move forward together.

Additionally, developing initiatives of alternative financing is a necessary requirement to achieve the objective of an adequate energy supply in developing countries. In order to attract private capital to renewable projects, the governments of these countries should promote public-private relations and financial plans based on micro-financing. Microfinancing can match the peculiarities of agricultural applications, providing a financial mechanism for end users.

There are at least three action levels on which effort should be concentrated: the development of public-private agreements of financing for rural energy supply projects; the increase in the role of international aid to provide the necessary conditions that stimulate the investment in the rural areas, and the impulse of models of innovative financing.

Financing is the main barrier for rural renewable energy projects, according to the survey of expert opinion reviewed above. Greater effort should be addressed towards attracting agents with the capacity of mobilising adequate financing: the private sector, governments and international institutions. In addition, the important quantity of resources that are channelled through foundations and non-governmental organisations should not be forgotten.

All of these actions require a new climate of cooperation, as well as the exchange of information and experiences. In this direction, several initiatives may be outlined. The first one would be the promotion of a Code of Good Practices in the area of rural energy development, by means of collecting the most noticeable cases of success anywhere in the world. The final product would be a methodology or a non-binding catalogue of key recommended considerations for starting programs of rural electrification. Particular aspects to be analysed should be the treatment of subsidies to conventional technologies, the registration of externalities, the monitoring of programme definition parameters, the matching between energy applications and rural exploitations, experiences in matter of training and local strengthening, links between energy ratios and productivity of exploitations, and especially, mechanisms for financing and organising the energy supply.

The second proposal would be in the development of an institutional platform oriented exclusively towards the issues related to the promotion of sustainable projects for energy supply in the agricultural field. This platform should make room for representatives not only of international agencies, but also from the private sector, the financial agents, the non-governmental organisations for development and especially important from the communities of beneficiaries. Particularly, it would be convenient that the platform include dedicated funds to finance actions oriented to increase the access to energy supply in isolated rural areas, so that all participating agents in the platform were linked directly 
with the projects, permitting at the same time different degrees of participation in each intervention.

In general, it may be claimed that the traditional intergovernmental processes of developing international policies in the area of agricultural development have not been completely efficient. New opportunities could be obtained from a multi-agent approach. The possibility of combining in a single effort the regulatory experience of the institutions with the capacity of mobilising funds from the private sector and the proximity to the final beneficiaries of the non-governmental organisations and local companies, taking into account the energy needs of beneficiaries, has not been sufficiently explored. Working with the single objective of improving the conditions of energy supply, and putting in common the strengths of all the participating agents in this task, would be a pioneering initiative.

In addition to supporting research and development, and the reinforcement of the regulatory framework in the developing countries, financing is a key aspect to set in motion global agricultural strategies. Therefore, it is necessary to consider new sources of financing for the energy sector and, still more important, to improve the basic conditions to attract investments towards the agricultural exploitations of developing countries.

\section{Conclusions}

Actions at three levels are needed. First, it is necessary to promote macro-economic policies in the developing countries that focus in the opening of markets in order to increase the liquidity of investments. It is also necessary to fight inefficiencies of many of these economies, in which no protection is offered by the legal systems (theft, nonpayment, corruption, etc). The correct redistribution of subsidies and incentives to the agricultural production, with special attention to the needs of the poorest segments of the population, would allow in many occasions the release of resources that may be reassigned to finance projects or to capitalise investment funds for projects in developing areas.

At the same time, a revision of the fiscal and regulatory policies should enable the elimination of some of the barriers that affect the process of technological transfer and the constitution of intermediary companies for financing. Overcoming these barriers would allow a better distribution of project risks among the different participating agents and an increase in the opportunities for developing long-term projects in proper conditions.

Concerning development finance and cooperation in the agricultural field, a change in the destination of funds is necessary. In the phase of transition towards a sustainable agricultural industry in developing countries, official aid should be oriented to support the most efficient and adequate technologies. The management of international aid should also be changed, so that not only isolated cooperation projects but also long-term interventions and programs can be funded. Involving international aid in micro-financing plans for projects of renewable energy could significantly increase the access of the poorest to new energy services (Fig. 6).

International aid can be an incentive to improve the institutional capacity of beneficiaries and to complement the national resources in order to cover the basic needs of the population. International aid should keep in mind that the main energy demand of the poorest continues to be for cooking, heating, and for agricultural exploitations. Interventions in the field of rural electrification should therefore not be considered as isolated activities; rather, they should be part of more extensive rural development programs. 


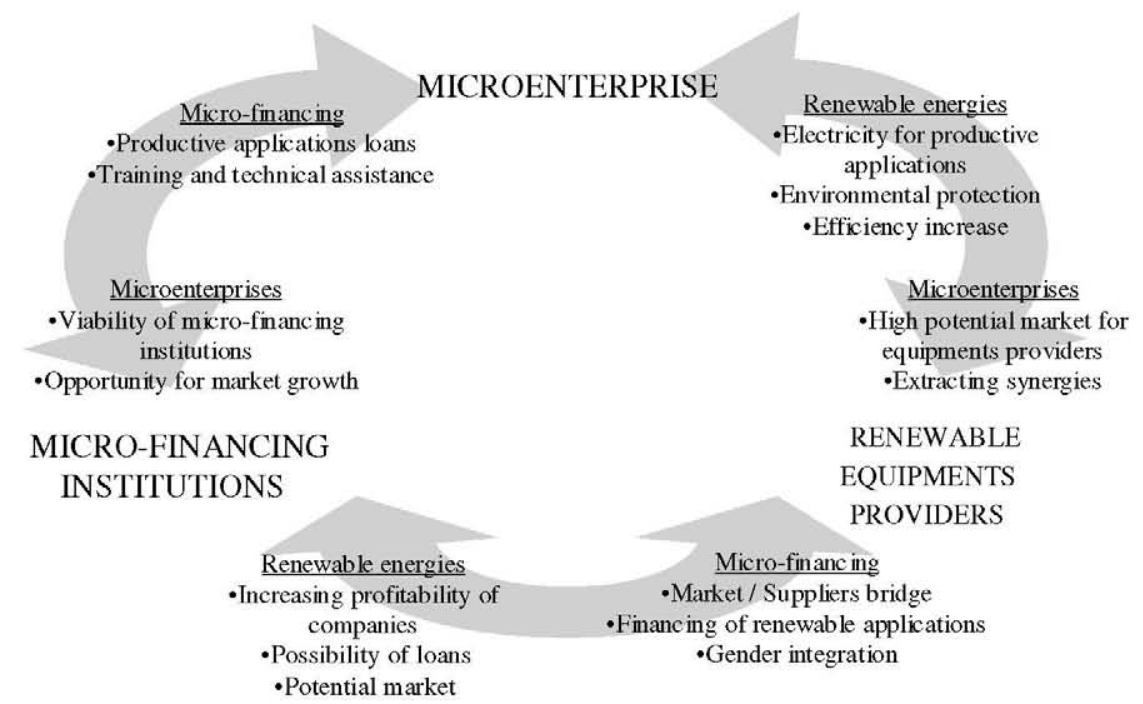

Fig. 6. Micro-financing and renewable technologies for rural applications synergies.

The problem is not only the lack of funds for investment but also the non-existence of proper conditions for investment in developing countries. An appropriate climate for investment would be based on various principles:

- recovery of the long-term costs;

- development of public-private mixed or hybrid structures for an appropriate distribution of risks;

- strengthening of cooperation relations among agents with complementary characteristics;

- legal and insurance coverage;

- backup of the public funds for the initiatives of public welfare, and

- commitment at a supranational level to increase the volume of resources devoted to improve the conditions of energy supply.

Taking into consideration all these determining factors, several proposals of action for the future can be made to improve of the sustainability of interventions:

1. A multi-level reinforcement of the coordination of the agents. This strategy of cooperation can be set at three levels. At a global level, by the international agencies and multilateral financial institutions; at a national or regional level, by the governments; and, at a local level, considering existing strategies and policies of rural development along with mechanisms of reinforcement of the domestic markets.

2. Actions oriented towards obtaining a regulatory and institutional reinforcement that increases the attractiveness of agricultural projects for private companies.

3. Promotion of innovative models of organisation and financing, allowing different levels of engagement with projects. 
4. Reinforcement of local training in the areas of management and mobilisation of resources, and especially in the efficient use of financial services adapted to the peculiarities of the cash flows of exploitations.

\section{References}

IEA. World energy outlook 2004. Paris: OCDE; 2004.

IEA. World energy investment outlook. OCDE: Paris; 2003.

Johansson $\mathrm{T}$, Mc Cormick $\mathrm{K}$. The potentials of renewable energy. In: International conference for Renewable Energies, Bonn, June 2004.

Beck F, Martinot E. Renewable energy policies and barriers. Encyclopaedia of Energy. San Diego: Academic Press/Elsevier Science; 2004.

Cabraal A. Decentralized electrification. Experiences and lessons learned. Energy and Water Department, World Bank 〈www.worldbank.org, 2003〉.

Boyle G. Renewable energy. Power for a sustainable future. United Kingdom: Oxford University Press, University of Oxford; 2004.

Harper M, Tanburn J. Mapping the shift in Business Development Services. New Delhi, India: ITDG, Samskriki; 2005.

Rodríguez Monroy C, San Segundo Hernández A. Survey of sustainability in rural energy supply projects. Results of the survey. Escuela Técnica Superior de Ingenieros Industriales, Universidad Politécnica de Madrid. March, Available at 〈http://www.gvep.org, 2005a〉.

Rodríguez Monroy C, San Segundo Hernández A. Developing sustainable electricity supplies in rural areas of developing countries. Electr J 2005;18(5):68-73 [Elsevier, Inc.].

Martinot E, Chaurey A, Lew D, Moreira JB. Renewable energy markets in developing countries. Annu Rev Energy Environ 2002;27:309-48.

Deloitte Touche Tohmatsu. Sustainable power sector reform in emerging markets. Financial issues and options. World Bank/USAID. 2004.

GNESD. Energy access theme results. Synthesis/compilation report. UNEP. April <http://www.gnesd.org, 2004>.

ITDG. Power to the people. Sustainable energy solutions for the world's poor. Rugby, UK <www.itdg.org, 2004>.

Winrock International. Monitoring and evaluation in rural electrification projects: a demand-oriented approach. World Bank, Winrock International, 2003.

IBRD, World Bank. Reforming infrastructure. Privatisation, regulation and competition. Washington, DC, 2004.

Sonntag-O'Brien V, Usher E. Mobilising finance for renewable energies. In: International Conference for Renewable Energies, Bonn, June (www.renewables2004.de. 2004).

Dunn S. Micropower. The next electrical era. Worldwatch. Paper 151, 2000.

Gore J. NGO-Private sector partnerships for rural energy finance. Winrock International Institute, 2002. 